\title{
Crisis, capital y comunicación en el 'estallido social' chileno (2019) ${ }^{1}$
}

\section{Crisis, capital, and communication in the 2019 Chilean uprising}

\author{
Jorge Valdebenito Allendes*
}

\begin{abstract}
RESUMEN
El 'estallido social' ocurrido en Chile durante el año 2019, ha suscitado una serie de interrogantes respecto a sus fuentes, manifestaciones y perspectivas de reestabilización. Este estudio presenta un examen crítico sobre la representación realizada por medios de comunicación de masas durante el transcurso de la rebelión. Concretamente, se atienden sus principales hitos y controversias. La ejecución del análisis involucra una comparación entre las coberturas periodísticas realizadas por cadenas de televisión abierta, con aquellas publicadas en periódicos con líneas editoriales politizadas. Los resultados indican que sus diferenciaciones se encuentran principalmente en las distinciones normativas subyacentes a la identificación del origen del estallido, caracterización de su propagación y proyección de alternativas de reestructuración. Tal normatividad se expresa en relativos énfasis y cegueras con que se presentan los hechos en sus tribunas. Y específicamente, en el caso de la televisión abierta chilena, se constatan adherencias manifiestas entre sus valoraciones y aquellas presentes en periódicos afines a la centro-derecha nacional. Desde ahí se discute sobre la caída en los indicadores de confianza en la televisión chilena, destacando la necesidad de democratizar sus perspectivas desde el pluralismo informativo.
\end{abstract}

Palabras clave: Crisis, estallido social, pluralismo informativo, Chile.

\section{Abstract}

Chile's social uprising in 2019 has raised a series of questions regarding its sources, manifestations, and prospects of re-stabilization. This study presents a critical examination of the representation made by mass media during the rebellion. Specifically, its main milestones and controversies are addressed. The analysis involves a comparison between the journalistic coverage made by open television channels, with those published in newspapers with politicized editorial lines. The results indicate that their differences are mainly found in the normative assumptions underlying the identification of the origin of the social outbreak, the characterization of its proliferation, and the projection of restructuring alternatives. Such normative assumptions are expressed in the way facts are presented in their stories, including partisan bias. In the case of Chilean open television, the results suggest a concordance with the views and opinions of the national center-right newspapers. On this basis, we discuss the increase of media distrust in Chilean television, highlighting the need to democratize its perspectives towards achieving media pluralism.

Keywords: Crisis, social uprising, media, media pluralism, Chile.

*jorge.valdebenito@postgrado.uv.cl 


\section{1.- INTRODUCCIÓN}

finales del año 2019 , Chile fue objeto de un inusitado
proceso de convulsión política y social. Como es de esperar,
esto ha provocado la publicación de una multiplicidad de análisis y aproximaciones. Entre aquellas provenientes del campo de las humanidades y ciencias sociales, estas se distinguen principalmente desde sus posicionamientos normativos. De una parte, estas caracterizan el proceso como irrupción de un escenario de caos y violencia, ante el cual la clase política fue incapaz de dar una respuesta adecuada (Peña, 2019; Rovira, 2020; Tironi, 2020). De tal incertidumbre e inestabilidad, la economía sufrió los principales efectos, disminuyendo sus proyecciones de crecimiento e inversión para el siguiente período (Gómez, 2019, 2 de diciembre; Marchetti, 2019, 21 de octubre).

De otra, se sostiene que el proceso revolucionario de octubre fue propagado por efecto de los resultados económicos, políticos y sociales, de la configuración neoliberal de las relaciones de explotación en el país (Akram, 2019; Grez, 2019; Torres, 2020). Tal postura orienta el presente documento. Allí, la violencia de su irrupción se explica por el descontrol impuesto por dicha configuración a las tendencias históricas del capital (Marx, 2010/1867; Solimano, 2014). Especialmente la acumulación, pauperización general del nivel de vida, proletarización de capas medias, degradación ecosistémica y aumento del ejército industrial de reserva. De ahí que el sujeto de la rebelión se conformara de un modo pluriclasista. Vale decir, en la articulación de descontentos populares y de sectores medios. Allí, cualquier estrategia seria de contención no podría formularse al interior de los límites del neoliberalismo. Con ello se justifica la construcción de un programa de transición antineoliberal, cuyas tácticas y estrategias deban definirse en el transcurso de su propia iteración.

Para comprender los diferentes aspectos del debate sobre la crisis y sus alternativas de salida, se pueden atender tres elementos clave (Mascareño, Goles y Ruz, 2016). Estos son i) la identificación de sus fuentes de incubación; ii) las valoraciones en torno a sus 
manifestaciones de propagación; y iii) adherencia o promoción hacia determinados caminos de reestabilización. La denominación del proceso como una explosión (Mayol, 2019), estallido (Akram, 2019), rebelión (Grez, 2019), convulsión (Torres, 2020), desborde (Tironi, 2020), crisis (Mascareño, 2020; Peña, 2019), entre otras (Fuentes, 2019; Herrera, 2019), no es baladí. Medios de masas como la televisión, en lugar de abrir un debate en la materia, han tendido a naturalizar la noción de 'estallido social'. A dicha comprensión conceptual subyace la impredictibilidad de lo sucedido, así como la invisibilización hacia el conjunto de fisuras del neoliberalismo chileno (Gaudichaud, 2015). Ampliamente estudiadas por diferentes organismos e intelectuales (CEP, 2017; Gárate, 2012; PNUD, 2017; Rovira, 2020), sus efectos han sido objeto de diferentes controversias mediáticas (Antezana y Cabalin, 2018; Cárdenas y Pérez, 2017; Gronemeyer y Porath, 2017; Sapiezynska, 2019) y representadas usualmente desde posturas afines a los intereses de la clase dominante chilena.

El objetivo principal del presente estudio es examinar los hitos y controversias que componen el llamado 'octubre chileno' del 2019 (Ruíz, 2020). Como fuente de información primaria se considera la representación mediática de sus hechos. Especialmente aquella realizada por la televisión abierta, considerada como el principal medio de información en el país (Newman, et al, 2020). Esto no excluye consideraciones a material proveniente de otros medios de prensa — como periódicos y/o radioemisoras—- además de informes gubernamentales, de organismos internacionales, estudios de opinión pública y publicaciones académicas. Sin embargo, el énfasis se encuentra en la dimensión mediática de la coyuntura. Esto, porque pese a ser considerado en análisis precedentes, no ha sido abordado desde una perspectiva crítica de la comunicación de masas. Desde ahí es clave cuestionar la normalización de determinadas posiciones afines a los intereses de los grupos propietarios de los sistemas mediáticos en formaciones democráticas (Becerra, 2019; Happer, 2016).

No es menor, en dicho sentido, el hecho que durante el 'estallido' 
las cadenas televisivas fueran objeto de críticas ciudadanas. Estas involucraron protestas en las afueras de sus instalaciones, campañas digitales de denuncia - con hashtags como \#LaTeleMiente-, sabotajes a despachos en terreno e intervenciones al aire en sets de televisión (Almeida y Riffo, 2019). Pero el empresariado también realizó sus maniobras, por ejemplo, mediante huelgas de inversión publicitaria en espacios televisivos, considerados ajenos a sus intereses editoriales (El Desconcierto, 2019a, 10 de noviembre). En resumen, la televisión quedó constituida durante la rebelión chilena del 2019 como objeto de lucha de clases (Lenin, 2003/1905; Marx, 2003/1871). Fundamentalmente por su función en la significación de procesos histórico-materiales. Pero pese a que las masas evidenciaron un salto en su conciencia respecto a la importancia de los instrumentos hegemónico-coercitivos, el 'octubre chileno' no logró una revolución triunfante. Por ejemplo, que destituyera el Gobierno burgués de Sebastián Piñera, e instalara en su lugar uno provisional de carácter revolucionario - $\mathrm{u}$ 'obrero y popular' (Torres, 2020).

No obstante, el movimiento sí planteó preguntas sobre el poder. Específicamente sobre las particularidades del enfrentamiento político, mediático y militar entre el sujeto del régimen y aquel de la insurrección (Lenin, 2003/1905; 2010/1902; Marx, 2003/1871). De tal colisión resultó la apertura de un proceso de recomposición institucional, diseñado al interior de los límites de la democracia burguesa (Lenin, 1961/1917). Y pese a permanecer interrumpido por la propagación del Covid-19 en Chile desde marzo del año 2020 (Valdebenito, 2020), sus potencias y límites requieren ser problematizadas. Aquí se presta especial atención al proceso que va desde la declaración del Estado de Excepción Constitucional (18 de octubre del 2019) hasta la firma del Acuerdo por la Paz y una Nueva Constitución (15 de noviembre del mismo año). El período previo y posterior a tal intervalo se analiza sucintamente.

A continuación se presentan algunas distinciones que subyacen al análisis (2), diseño metodológico (3), resultados (4) y una síntesis de discusiones abiertas a modo de conclusión (5). 


\section{2. - Distinciones analíticicas}

2.1. Crisis y Capital en las batallas ideológicas.

Desde el origen griego del término, la crisis, remite a una situación de emergencia, ante la que se requiere una intervención urgente (Koselleck, 1998; Standring y Davies, 2020). Tal nomenclatura médica sigue las distinciones realizadas por Hipócrates durante la época clásica. Sea en cuerpos biológicos o sociales, fundamental es distinguir síntomas visibles de la enfermedad que los origina. Para muchos/as analistas críticos/as, la consolidación del modo de producción capitalista a nivel mundial ha intensificado $y$ acelerado la sucesión de episodios de crisis de todo tipo (Arboleda, 2020; Foster, 2016). Su origen se encontraría en la combinación de contradicciones políticas, sociales y ambientales propias del ordenamiento vigente de la economía mundial. Dicha aseveración no está exenta de controversias. La situación abierta tras la crisis financiera del año 2008 (Roberts, 2018), donde cabe el estallido social chileno del año 2019, para algunos neogramscianos expresa la crisis orgánica del globalismo neoliberal (Stahl, 2019). Para otros, más bien la crisis actual de la democracia liberal (Castells, 2017), o por el contrario, los efectos del incremento de la complejidad de las relaciones sistémicas en la sociedad mundial (Mascareño, 2018).

A la explicación respecto de las crisis, subyacen criterios de carácter cognitivo-normativos, que colisionan durante los procesos de debate o controversia (Luhmann, 1984; Mascareño, 2020). Es central comprender que en formaciones de clase, dicho fenómeno contiene elementos que los grupos dirigentes intentarán marginar. Según diversos estudios, dicha tarea recae en los instrumentos de propagación ideológica, así como de producción cultural (Boulianne, et al, 2020). En la era contemporánea y pese al progresivo aumento de la importancia de plataformas como Internet, la televisión abierta mantiene su posición preponderante (Newman, et al, 2020). Esto principalmente gracias a la adaptabilidad de sus cadenas, la cual ha involucrado, por ejemplo, prácticas de reconversión a las nuevas plataformas. En cuanto a la representación de las coyunturas económico-políticas, particular importancia poseen los espacios de 
debate y análisis de actualidad. Allí son expuestas las tesis explicativas de lo social, admisibles, elaboradas y/o permitidas por los grupos dominantes (Habermas, 2006). Posiciones y análisis fuera de tales límites, son marginados mediante diferentes mecanismos de exclusión, contraviniendo los principios democráticos de apertura y pluralismo que la propia sociedad burguesa se jacta de promover (Happer, 2016).

Las prácticas de resistencia a la hegemonía mediático-capitalista son diversas. Estas van desde la construcción de medios alternativos y/o independientes, hasta la lucha institucional por la promoción y respeto a los derechos de la comunicación. Vale decir, la facultad ciudadana a informar y ser informada. Pero ambos repertorios poseen limitaciones prácticas. El primer caso impulsa la tendencia a la atomización mediática. Esta se reconoce como condición para la consolidación de fake-news y post-verdad (Newman, et al, 2020). También facilita la 'naturalización' de la exclusión a determinadas miradas en medios masivos, desplazando su circulación hacia medios de nicho. De ahí la importancia de democratizar los sistemas mediáticos, por sobre fomentar el paralelismo informativo. No obstante, las luchas reivindicativas por 'leyes de medios' han evidenciado debilidades históricas. En los casos de Argentina y Ecuador, donde fueron levantadas por gobiernos progresistas (Becerra, 2019), al poco andar las oligarquías locales encontraron diferentes formas de desmantelarlas.

El caso chileno es icónico en cuanto a la acumulación de capital y poder mediático. Conglomerados como Quińenco, CorpGroup, Bethia y transnacionales como AT\&T, controlan además de las comunicaciones, la propiedad de las plataformas de circulación de estas. Poseen además de buena parte de las empresas de la industria, comercio y finanzas locales. Dicha oligopolización ha sido denunciada como contraria a la preservación democrática de los derechos a la información, especialmente durante episodios de convulsión o protesta social (Almeida y Riffo, 2019; El Desconcierto, 2019a, 10 de noviembre). Diversos estudios identifican el origen de tamaña concentración en la neoliberalización de las relaciones 
de explotación en Chile (Gaudichaud, 2015; Mayol, 2019; Ruíz, 2020). Su antonomasia es el 'ladrillo' de la dictadura militar (1973-1990) (De Castro, 1992; Gárate, 2012), cuyos pilares han permanecido incólumes desde los gobiernos de la transición concertacionista (1990-2010) (Pressacco y Salvat, 2012). Ante ellos, los movimientos de rechazo al continuismo han sido usualmente representados televisivamente desde el descrédito y criminalización (Antezana y Cabalin, 2018; Cárdenas y Pérez, 2017; Gronemeyer y Porath, 2017; Sapiezynska, 2014). Esto constituye antecedente para entender la significativa reducción en los los niveles de confianza y legitimidad ciudadana hacia las plataformas del sistema mediático convencional en Chile durante la última década (Activa, 2020; Newman, et al, 2020).

\subsection{Comprendiendo el 'estallido social' del 20 i9 en Chile}

Diferentes diagnósticos, previos al 'estallido' del 2019, indicaron un agotamiento de las potencias del neoliberalismo chileno (Gaudichaud, 2015; Tironi, 2020). Desde la defensa a dicho modelo, sus portavoces destacan la capacidad de desarrollo de la economía de mercado para el país (Herrera, 2019; Peña, 2019). Ejemplos de ello se encuentran en materia de urbanización, aumento de acceso a servicios básicos e incremento de la cobertura en prestaciones como salud y educación. Tales logros se asocian a la configuración de una economía abierta, con bajos niveles de corrupción, consolidación de la austeridad y rol subsidiario del Estado (Fuentes, 2019). Entre sus falencias se reconoce la agudización de los indicadores de desigualdad socioeconómica y un decrecimiento en aquellos de confianza en las instituciones democráticas. Con todo, se destaca que las capas vulnerables hoy gozan de un mejor nivel de vida que sus antepasados. Así, tanto el crédito como la financiarización, se reconocen como claves en la reducción de la 'extrema pobreza' en el Chile post-dictatorial.

Pero tales reconocimientos colisionan con aquellos sobre los efectos de las fisuras, o fragilidades, de la neoliberalización (Akram, 2019; Grez, 2019). Desde ellos, el descontrol, o absoluta 
hegemonía empresarial sobre la configuración de las relaciones de explotación en Chile, ha terminado por exacerbar las tendencias históricas del desarrollo capitalista (Solimano, 2014). Entre ellas, la pauperización general del nivel de vida de la población, pero muy especialmente la proletarización de las capas medias. Esta sería la condición del debilitamiento del consenso pro-neoliberal al interior de la clase dominante chilena. Su tradicional línea de masas, objeto de la polarización inducida por la acumulación, imposibilitada se encuentra hoy de reconocer como propios los intereses del latifundio y la burguesía. Pero por la historia de la conciencia de clase de tales sectores, poco probable es que enarbolen las causas del socialismo. De ahí que ante la inestabilidad de la república liberal, fracciones de la pequeńa burguesía urbana y rural tiendan a respaldar iniciativas de carácter proto fascistas.

Ejemplos de lo anterior se encuentran en el 8\% electoral de José Antonio Kast en el año 2017. También la articulación en curso de grupos de extrema derecha (Collados, 2020) — como Voz Nacional y Capitalismo Revolucionario-, con medios de información particulares - como El Baquedano- y presencia en gremios empresariales - como camioneros y agricultores. A ello se suma el clima de violencia en el Wallmapu. En suma, el surgimiento del paramilitarismo en el Chile del post-estallido 2019 figura como una probabilidad en la nación sudamericana. Considerar además que la rebelión chilena del 2019 fue codificada por dichos sectores como expresión de delincuencia y vandalismo (Aurora Soberana, 2019). Desatendiendo las contradicciones del neoliberalismo, atribuyeron el movimiento de masas a la acción de revolucionarios profesionales entrenados en el extranjero. Específicamente, provenientes de Cuba, Nicaragua y Venezuela. De ahí que por sobre promover la implementación de medidas democratizantes y redistributivas, aludan a la 'mano dura'. Para tales sectores, la administración de Sebastián Piñera ha caído en un 'entreguismo a la izquierda y órganos globalistas de derechos humanos', ante lo cual 'al ciudadano de a pie no le quedaría más que defenderse'.

Tras la última gran crisis financiera del 2007-2009 (Roberts, 
2018), la clase capitalista mundial ha demostrado insuficiencia en la gestión de los efectos negativos de su modo de producción (Callinicos, 2015). Pese a diagnosticar las consecuencias del descontrol sobre los cambios técnicos (Arboleda, 2020), climáticos (Folke, et al, 2016; Foster, 2016) y demográficos (Rigaud, et al, 2018), no ha logrado ejecutar acciones ecuánimes al respecto. Esto ha propiciado el empeoramiento de una serie de conflictos de todo tipo en el mundo capitalista. Difícilmente estos puedan ser reducidos a grosso modo como expresión del incremento en la complejidad de las relaciones sistémicas transnacionales (Mascareño, 2018). Con todo, diferentes corrientes liberales apelan a recomponer los sistemas institucionales en una dirección democratizante(Castells, 2017; Mouffe, 2007; Mudde y Rovira, 2018; Stahl, 2019). En general, orientada a promover la participación ciudadana en la toma de decisiones, y la protección vía derecho de ciertos bienes y servicios sociales.

Tal orientación subyace en Chile a la reivindicación por un 'nuevo pacto social', materializada en el Acuerdo por la Paz y una Nueva Constitución el 15 de noviembre del año 2019. Si bien dicho proceso ha sido denunciado por ciertos sectores como tendiente al colaboracionismo de clase (Grez, 2019), lo cierto es que su realización se encuentra revestida de una enorme incertidumbre y complejidad. De una parte por la propagación del Covid-19 (Valdebenito, 2020), pero también por la multiplicidad de contradicciones históricas no encaradas por el régimen (Torres, 2020). Ambos elementos son fuente de inestabilidad en la nación sudamericana. El análisis de hechos y sus respectivas representaciones en los medios de comunicación de masas, permite balancear la formulación de preguntas y el modo de enfrentarlas (Mascareńo, 2020). Esta es la tarea que el presente estudio se propone ejecutar.

\section{3. - Diseño MetodolóGico}

El objetivo general de la presente aproximación es caracterizar el 'estallido social' chileno del año 2019, desde la representación mediática de sus principales hitos y controversias. Esto, fundamentalmente, a partir de los debates en torno a sus 
fuentes de incubación, expresiones de propagación e intentos de reestructuración. Es una preocupación del estudio atender los respectivos énfasis y cegueras con que el conjunto mediático chileno representó la crisis desde sus plataformas. Se estima conveniente centrar el análisis en la cobertura televisiva, por tratarse del principal medio de información en el país (Newman, et al, 2020). Para reconocer sus lineamientos, se considera pertinente contrastar sus contenidos con aquellos producidos por ciertos periódicos digitales afines a determinadas líneas normativas. El interés de ello reside en identificar cercanías entre las representaciones televisivas con otros medios. Concretamente, en el modo de significar determinadas coyunturas críticas.

Como técnica de investigación se emplea el análisis comparativo de contenidos periodísticos (Eiroa y Barranquero, 2017). La muestra es intencionada y centrada en la relevancia de la fuente de información. Esto quiere decir que, por sobre la revisión exhaustiva del material, se examinan sucesos que permiten caracterizar la coyuntura desde sus puntos de inflexión (Martínez-Salgado, 2012). La unidad de observación corresponde al material publicado por los medios integrados en el diseño muestral (Figura 1). Las cadenas de televisión seleccionadas son Televisión Nacional de Chile (TVN), Mega, Chilevisión (CHV), CNN Chile y Canal 13. Es de interés analítico examinar especialmente los contenidos publicados por TVN, dada su misión y visión pública (TVN, 2020) y las razones expuestas en el apartado 2.1. Entre los periódicos digitales se seleccionaron preferentemente notas y columnas publicadas por $\mathrm{El}$ Mercurio (y su versión digital, Emol), El Líbero y Diario Financiero - en tanto medios cercanos a la derecha política chilena- y El Desconcierto, Ciper e Interferencia — como medios afines a la izquierda progresista chilena. Esto no excluye referencias a otros medios, cuyo material ha sido considerado en menor medida. 
Figura 1. Diseño muestral.

\begin{tabular}{|c|c|c|c|c|c|}
\hline \multirow{2}{*}{$\begin{array}{c}\text { Fase } \\
\text { corona-crisis }\end{array}$} & \multicolumn{2}{|c|}{$\begin{array}{c}\text { Notas publicadas } \\
\text { en TV chilena }\end{array}$} & \multicolumn{2}{c|}{$\begin{array}{c}\text { Notas publicadas en } \\
\text { periódicos digitales } \\
\text { escogidos }\end{array}$} & \multirow{2}{*}{ Total } \\
\cline { 2 - 5 } & $\begin{array}{c}\text { TVN } \\
\text { (Tv pública) }\end{array}$ & $\begin{array}{c}\text { Otras cadenas } \\
\text { (tv corporativas) }\end{array}$ & $\begin{array}{c}\text { Periódicos } \\
\text { de izq }\end{array}$ & $\begin{array}{c}\text { Periódicos } \\
\text { de der }\end{array}$ & \\
\hline Incubación & 4 & 1 & 0 & 0 & 5 \\
\hline Propagación & 5 & 14 & 10 & 7 & 36 \\
\hline Reestructuración & 2 & 6 & 9 & 10 & 27 \\
\hline Total & 11 & 21 & 19 & 17 & $\mathbf{6 8}$ \\
\hline
\end{tabular}

Fuente: Elaboración propia.

El análisis se inspira en los criterios de un modelo trifásico de los procesos de crisis, que comprende subperíodos de incubación, propagación y reestructuración (Mascareño, et. al, 2016). La articulación de estos elementos origina casilleros tipológicos (Strauss \& Corbin, 2002). Los tamaños muestrales de cada uno de estos se han fijado según saturación de información (Figura 1). Vale decir, una vez que la inclusión de nuevas unidades muestrales no aporta nuevos antecedentes al estudio. Debe señalarse igualmente que se ha descartado aquí ejecutar cualquier tipo de análisis del discurso, semiótico — de la imagen y/o textual—, o estadístico. Tales aplicaciones permanecen como sugerencia para futuras indagaciones. El presente examen corresponde más bien a una revisión de sucesos, y sus respectivas representaciones. Esto principalmente desde medios de prensa chilenos, aunque se atienden otras fuentes, como informes gubernamentales y de organismos internacionales, estudios de opinión pública y artículos académicos. El ejercicio en sí se plantea como la realización de un estudio interdisciplinario sobre una coyuntura de crisis política y social, que integra elementos de las ciencias sociales y de la comunicación (Osborne, 2015). Los resultados se presentan en los siguientes subapartados del punto 4 . 


\section{4.- Resultados}

\subsection{InCUBACIÓN}

El período de incubación comprende el despliegue de una serie de procesos cuyo 'estallido' se materializó en la rebelión chilena de octubre y noviembre del año 2019 (Grez, 2019; Mayol, 2019). El examen de tales elementos ha permitido confirmar los análisis sobre, las contradicciones y/o fisuras del neoliberalismo chileno (Gaudichaud, 2015), que han sido desatadas por las tendencias históricas de la acumulación capitalista (Marx, 2010/1867; Solimano, 2014). Entre estas destacan: i) la acumulación; ii) pauperización de las condiciones de vida; iii) proletarización y/o desaparición de las capas intermedias entre burguesía y proletariado - como campesinado y pequeña burguesía industrial, comercial y financiera-; y iv) polarización de las distancias relativas (o 'desigualdades') entre estas últimas. A ello se suma la aceleración e intensificación de los episodios de crisis (Roberts, 2018), deprivación general, desestabilización institucional y radicalización de los métodos de lucha entre los diferentes grupos y/o sectores político-sociales (Castells, 2017; Lenin, 2014/1915; Stahl, 2019).

Tras las rebeliones estudiantiles en Chile (2006-2011), toda índole de analistas políticos y sociales ha enfatizado en los medios de comunicación sobre la necesidad de ejecutar intervenciones profundas sobre el modelo económico chileno (Rovira, 2020). Principalmente en materias de democratización y redistribución. No obstante, dichos llamados han sido sistemáticamente desatendidos por la clase dominante del país (Herrera, 2019). Al respecto, los miembros de ésta última han insistido en que las deficiencias del modelo se pueden resolver con estímulos al crecimiento y/o productividad económica. En su mirada, fundada sobre los principios del monetarismo, el libre flujo y autorregulación de los mercados garantizan un mejor nivel de vida en el largo plazo para la población (De Castro, 1992; Gárate, 2012).

Lo anterior ha sido cuestionado en diferentes espacios televisivos. Por ejemplo, en episodios como 'Súper ricos en un país desigual', de Informe Especial (Acevedo, 2012, 12 de julio) y 'Una vida rodeada 
de lujos' de 21 días (TVN, 2017). Allí se destacan las inequidades comparativamente superiores del capitalismo chileno respecto de otras naciones avanzadas, como aquellas integrantes de la OCDE. Ello confirma que las disputas en torno a la significación de los efectos del modelo chileno de desarrollo son múltiples. Diferentes estudios han demostrado que en televisión ha triunfado la posición que tiende a criminalizar las manifestaciones de descontento popular (Antezana y Cabalin, 2018; Sapiezynska, 2014). Durante tales episodios, es frase recurrente 'la reclamación es justa, pero no es la forma'. Reiterada durante protestas estudiantiles, ecologistas, feministas, de pueblos originarios, sindicales, entre otras (Cárdenas y Pérez, 2017; Pinto, 2019), su enunciación contraviene el seguimiento de las misiones públicas y democráticas de los medios de masas. De ahí que una serie de sectores sociales manifiesten su descontento con tal cobertura, denunciando a los medios ante instancias como el Consejo Nacional de Televisión (CNTV) por sus faltas de probidad en su gestión informativa.

Entre la bibliografía consultada, la fuente de lo anterior es usualmenteidentificada desdela prevalencia de intereses empresariales en las cadenas de televisión (Becerra, 2019; Gronemeyer y Porath, 2017). También se indica que dichos interesados logran primar entre algunos de los think tanks más influyentes en Chile (Morales, 2018). Especialmente aquellos dedicados al estudio de la realidad económica y política local. Y, de tal modo, son los/as expertos/as de tales organizaciones los/as que gozan de tribuna privilegiada entre los principales medios de difusión de contenidos en el país. Parte, o no, del llamado clivaje entre política y sociedad (Ruíz, 2020), la consecuencia práctica ha sido la articulación de un escenario de 'crisis orgánica' y/o de legitimidad del régimen chileno (Fuentes, 2019). Algunos efectos se reconocen en el abstencionismo electoral y pérdida de confianza en el sistema de partidos (Mayol, 2019; Peña, 2020; Rovira, 2020). Tal elemento es clave para comprender las dificultades de la institucionalidad burguesa para descomprimir al interior de sus límites la violencia popular desatada durante la insurrección del 2019. 
Cuando esta toma lugar, la coyuntura política nacional se encuentra debatiendo la implementación de una serie de contrarreformas oficialistas al legado del bacheletismo (2014-2018). Particularmente mediáticas son las reformas tributaria, previsional, laboral y del sistema de capacitación —o de educación para el trabajo, SENCE (Doniez y Gálvez, 2020). Notoriedad adquieren iniciativas como la 'sala cuna universal' y 'estatuto joven', promovidas asiduamente por el entonces ministro del Trabajo y Previsión Social, Nicolás Monckeberg. Este suele figurar en espacios como matinales (TVN, 2019) y noticieros (24horas.cl, 2019a), donde sus propuestas son insuficientemente abordadas — por ejemplo, respecto a su profundidad y contexto internacional (IMF, 2019, 19 de junio). La respuesta obrera ante estas maniobras se materializó con la 'huelga del futuro', protagonizada por el principal sindicato de Walmart en el país, en julio del 2019 (CNN Chile, 2019a, 10 de julio). Esta ocurrió ante el rechazo de las medidas tendientes a incrementar la composición orgánica del capital en los supermercados Líder (Arboleda, 2020).

Los medios no destacan que el mundo capitalista no ha podido superar los efectos de la última gran recesión del 2007-2009 (Roberts, 2018). A ello se suma la intensificación de la guerra comercial entre China y Estados Unidos. En dicho escenario, los gobiernos neoliberales, por sobre adoptar medidas contracíclicas, han paliado la crisis con capital ficticio, mediante créditos y financiarización. Resultado de ello ha sido el incremento en la frecuencia, extensión e intensidad de las crisis capitalistas en el siglo XXI. Al respecto, la interpretación sistémica sostiene que esto se debe más bien a la complejización, y consecuente inestabilidad, de las relaciones actuales en la sociedad mundial (Mascareño, 2018; 2020). Si bien dicha lectura es potente para analizar la rebelión de octubre, margina de su centro los límites y contradicciones de las dinámicas de reproducción ampliada del capital (Marx, 2010/1867; Solimano, 2014). Y tal exclusión no permite comprender adecuadamente la insuficiencia de las reformas subsidiarias y/o monetaristas que intentan detener el 'lado oscuro' (Teubner, 2012) del desarrollo capitalista. 
En primer lugar, el avance del reemplazo de trabajo vivo por maquinaria (sea por digitalización, robotización, u otras innovaciones técnicas del capital) ha incrementado significativamente los ejércitos industriales de reserva en el mundo moderno (Arboleda, 2020). Segundo, la degradación de la naturaleza, inducida por el extractivismo, ha inhabilitado además la reproducción ecosistémica en extensas zonas geográficas (Foster, 2016). Y tercero, de la combinación de estos elementos, se han originado una serie de transformaciones demográficas. Entre ellas, caídas en las tasas de natalidad y migraciones climáticas. Estas desafían la realización de proyectos de bienestar en las economías avanzadas, y de transformación de matrices productivas en economías emergentes (Rigaud, et al, 2018). En el caso chileno, las manifestaciones de estas transformaciones globales se encuentran desigualmente combinadas. Por ejemplo, según capa y región en el país. Comunidades del norte deśertico sufren efectos de sequías y contaminación de la megaminería, en el centro sur la agroindustria y forestales replican un escenario similar, y las acuícolas en mares patagónicos.

Lo anterior ha sido ampliamente discutido como expresión material de la contradicción entre vida y capital. A tal constatación subyace el llamado a implementar medidas conducentes hacia la construcción de un nuevo modelo de desarrollo (Akram, 2020; Mayol, 2019; Solimano, 2014). Su horizonte, junto con gestionar las paradojas de la modernización, sería realizar las promesas incumplidas de la Ilustración — libertad, igualdad y fraternidad-, además de compatibilizar las relaciones productivas entre naturaleza, trabajo y capital (Foster, 2016; Marx, 2010/1867).

Por el contrario, la orientación sistémica sostiene que tal perspectiva es irrealizable. En lugar de ello, propone adaptarse a coexistir con los dilemas actuales de la sociedad capitalista (Mascareño, 2018; Folke, et al. 2016). Su recomendación es la coordinación y diferenciación funcional. No obstante y pese a tener buena acogida entre las clases capitalistas, las iniciativas diseńadas en su nombre han sido infructíferas (PNUD, 2017; CEP, 2017). Se debe evaluar en detalle a qué responde tal lamentable resultado. 
Pero desde una perspectiva crítica, se puede anticipar que por sobre mitigar el conflicto social, sus orientaciones tienden a reproducir las asimetrías y deficiencias propias del capitalismo mundial. Y aquí, estas últimas son comprendidas como fuentes generales del proceso revolucionario del año 2019 en Chile (Ruíz, 2020; Torres, 2020).

\subsection{Propagación}

El período de propagación aquí será codificado como aquel dado entre el inicio de los primeros indicadores de un 'estallido social' en Chile, y la firma de un acuerdo entre el Ejecutivo y Legislativo para contener la rebelión. Dichos primeros indicadores son protagonizados por estudiantes secundarios. Sus registros datan desde el día 7 de octubre del ańo 2020 (Interferencia, 2019, 20 de octubre). Consisten en manifestaciones semi-espontáneas en las estaciones de la red de tren urbano, Metro. Su reclamación es contra el anuncio de alza en las tarifas del transporte urbano. La consigna 'evadir, no pagar, otra forma de luchar' toma fuerza entre las masas. Los hechos adquieren pronta notoriedad en plataformas digitales como Facebook, Instagram y Twitter. La prensa burguesa atiende someramente estos hechos. No vaticinan el salto que experimentará la movilización en los próximos días. En pantalla se proyectan declaraciones divididas entre los transeúntes (Canal 13, 2019). Estos en general validan la lucha, cuyo trasfondo es el incremento en el costo de la vida propiciado por el avance de las ofensivas neoliberales. Pero cuestionan la 'violencia' de los métodos, donde la máxima 'no es la forma' resuena como eco del peso de la noche portaliano (Edwards, 1976; Grez, 2011). Aún así, las masas evidencian conciencia de su situación de vulnerabilidad ante los 'abusos' de la clase dominante (CEP, 2016; Peña, 2019).

Durante la jornada de análisis político en televisión del día domingo 13 de octubre, en Mesa Central (T13, 2019a, 13 de octubre) y Estado Nacional (24horas.cl, 2019b), se atienden algunas exteriorizaciones vigentes de las contradicciones de clase del régimen chileno. Una de ellas corresponde a las 'balas locas' en barrios periféricos de la ciudad de Santiago de Chile. Otra es el rechazo de 
sectores de las élites a extender la red de estaciones de Metro hacia sus perímetros residenciales. Los análisis en pantalla evidencian una comprensión inacabada de estos fenómenos. En su lugar reiteran la necesidad de ejecutar fórmulas que impulsen el desarrollo neoliberal. Por ejemplo, desde el fomento a la productividad, austeridad y flexibilidad laboral. La contraparte a tales orientaciones se observa en las calles del país durante el transcurso de la semana. En la medida que las movilizaciones toman impulso, el Gobierno responde con demagogia y represión (CHV Noticias, 2019, 17 de octubre).

El día viernes 18 de octubre, la rebelión de las masas arranca estrepitosamente en el espacio público (T13, 2019b). La crisis se manifiesta como exteriorización de las contradicciones históricamente ocultas, o negadas, por la clase capitalista durante los períodos de bonanza económica (Marx, 2010/1867, pp. 11-22). Los hechos hablan, desde una perspectiva leninista, de la apertura de una situación revolucionaria (Lenin, 2014/1915). El régimen entra en un momento de alta inestabilidad, propiciada por la movilización de masas, tras ańos de soportar una continua pauperización de sus condiciones de vida. Las escenas en televisión exhiben la quema de estaciones de Metro, decenas de heridos y mutilados durante enfrentamientos con la policía, además de una rápida militarización en 'zonas de conflicto' (24horas.cl, 2019c; CNN Chile, 2019b, 19 de octubre). Al despliegue del 'bonapartismo' del Ejecutivo (Marx, 2003/1871), sucede el presagio del fin de la era neoliberal en Chile. El 'oasis' latinoamericano es hoy objeto de una entrada violenta de las masas por el gobierno de sus destinos. Ante esta, la clase dirigente observa atónita, y se muestra incapaz de codificar oportunamente lo que se presenta ante sus ojos (Meganoticias, 2019a, 8 de octubre).

El Ejecutivo declara precipitadamente el Estado de Emergencia (Navarro y Tromben, 2019), reintroduciendo al factor militar como garante del orden institucional. Algunos/as sostienen que esto se explica como una decisión economicista, que atiende las reacciones bursátiles ante las imágenes de la insurrección en la prensa internacional (Marchetti, 2019, 21 de octubre; Velasco, 2019, 18 de octubre). Indicadores son la caída del IPSA de casi 
un 5\%, junto a un alza del tipo de cambio y del riesgo país (Figura 2). Los/as especialistas auguran fuga de capitales, aumento en las proyecciones del desempleo y de la caída del producto. Prontamente las cumbres internacionales COP-25 y APEC 2019 son canceladas. En medio de la confusión, el Gobierno revive la nomenclatura de la Doctrina de Seguridad Nacional de la dictadura. Atribuye el caos a una cooperación entre inteligencia extranjera y el crimen organizado local. Pero no hay denuncias ante la ONU por intervencionismo foráneo, sino un audio de la Primera Dama explicando los hechos como una 'invasión alienígena' (Romero, 2019, 23 de noviembre).

Figura 2. Indicadores IPSA, Tipo de Cambio y Riesgo País. OCtubre 2019

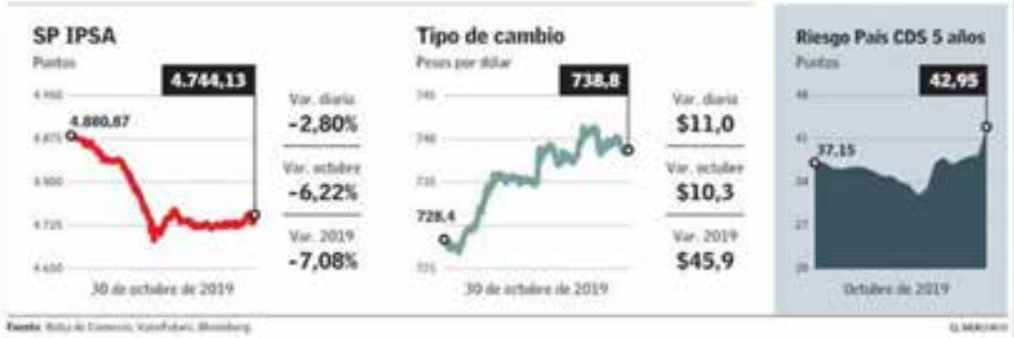

Fuente: El Mercurio (2019, 3 I De octubre).

La criminalización de la protesta social justifica su represión. Pero los aparatos de seguridad estatal son resistidos por una población que porta el aprendizaje de años de lucha callejera (24horas.cl, 2019d; Meganoticias, 2019b). En la práctica, sus elementos parecen superar su histórica 'tendencia al reposo' (Pinto, 2011). A las consignas de 'No son \$30, son 30 años' se suman cánticos que indican 'Chile despertó'. El Presidente Piñera, en un acto fallido por descomprimir la rebelión, declara la guerra al pueblo movilizado. Sin embargo, el recientemente nombrado Jefe de la Defensa Nacional, General Iturriaga, se desmarca de los dichos. Este indica 'no estoy en guerra con nadie, soy un hombre feliz' (CNN Chile, 2019c). Pronto circularán imágenes de militares jugando voleibol con la población 
en Viña del Mar (El Dínamo, 2019) y levantando banderas mapuche en Puente Alto (El Mostrador, 2019, 24 de octubre). También un caso de insubordinación en el Ejército, ocurrido en Antofagasta (El Desconcierto, 2019b, 8 de noviembre). ¿Se abre paso a la deliberación en las Fuerzas Armadas? (Salazar, 2019; Torres, 2020). Solo la historia responderá tal interrogante. Pero lo concreto es que en menos de dos semanas los militares serán replegados de las calles. En su lugar, la policía es reforzada, al momento que la lucha popular suma adherentes entre las masas (Activa, 2019; Romero, 2019, 26 de octubre).

La rebelión obliga a la clase política a diseñar una fórmula de descompresión. Pero el Ejecutivo se muestra desesperado, y parece sólo disponer de la represión. Por momentos figura como si fueran sólo la policía y militares quienes sostienen al Gobierno (Torres, 2020). El pueblo movilizado 'desborda' lo establecido (Peńa, 2019; Tironi, 2020). Sus elementos se presentan como portadores del aprendizaje histórico de luchas contra el poder oligárquico. La oposición parlamentaria patentiza sus diferencias políticas e ideológicas. Incluso, ciertos sectores exhiben mayor afinidad con el bloque dominante (Gaudichaud, 2015; Stahl, 2019). La Democracia Cristiana apoya la Nueva Agenda Social del Gobierno, mientras la Convergencia Progresista (PS-PR-PPD), Frente Amplio y Partido Comunista, proponen una Nueva Carta Magna (Marín, 2019a, 14 de noviembre). La disputa entre dichas orgánicas versa sobre el o los mecanismos para redactarla.

En paralelo, los medios de masas destacan la violencia de las movilizaciones. Imágenes de saqueos, destrucción de viejos signos patrios y del colonialismo, junto a declaraciones de rechazo hacia los métodos de la lucha popular, saturan las pantallas. En medios digitales se denuncia la proliferación de grupos de autodefensa territorial, pero con una orientación proto-fascista. Los 'chalecos amarillos' se erigen en barrios residenciales de sectores medios (Avendaño, 2019, 22 de octubre). Preliminarmente, puede sostenerse que están compuestos por lo que fuera la vieja línea de masas del pinochetismo (Aurora Soberana, 2019). Militares activos y en retiro, pequeńos y medianos 
locatarios, latifundistas, comerciantes y cuentapropistas, se articulan para enfrentar las 'hordas de delincuencia' de la rebelión (CNN Chile, 2019d). Pero la marcha del 25 de octubre logra dar un golpe a tales caracterizaciones, aunque no exenta de contradicciones. La concentración más grande de la historia de Chile, se materializa como un enorme acto pacífico de masas (Chilevisión, 2019). El Gobierno aprovecha el flanco abierto. Intenta subsumir la manifestación con un discurso democratizante (T13, 2019c, 25 de octubre).

A su vez, toman impulso las negociaciones entre Ejecutivo y sectores colaboracionistas de la oposición parlamentaria (Díaz, 2019, 26 de octubre). La movilización, pese a su volumen, no logra dar un salto en calidad por sobre cantidad (Lenin, 1902/2010; Torres, 2020). La opinión pública respalda las manifestaciones, pero no sus expresiones de violencia ni la represión policial (Activa, 2019). Andrés Chadwick, primo del Presidente y entonces Ministro del Interior y Seguridad Pública, es removido del cargo el lunes 28 de octubre. Es el primer chivo expiatorio de la situación. Las organizaciones agrupadas en Unidad Social procesan la disyuntiva. Todo indica que es requerida la entrada coordinada de trabajadores y trabajadoras de los sectores productivos. Esto a modo de evitar que el 'estallido' sea contenido y desviado por el Ejecutivo y sus fuerzas auxiliares en el Legislativo. El objetivo es dar un golpe clave al Gobierno, saboteando el curso de la reproducción ampliada del capital en Chile (Ruiz, 2020; Solimano, 2014).

La Huelga General será concertada para el día 12 de noviembre del 2019 (24horas.cl, 2019e, 12 de noviembre). En el intertanto, el régimen despliega un discurso pacifista, mientras la televisión redunda en imágenes de saqueos, cócteles molotov y policías 'superados por la muchedumbre' (Meganoticias, 2019c). Por momentos pareciera que esta última se encuentra generando las condiciones que legitimen una escalada violenta de la represión. Al día 28 de octubre, las cifras hablan de 19 muertos, 60 casos de mutilaciones o daños oculares, más de mil heridos y tres mil detenidos. Además sse publican denuncias por tortura y violación a manos de Carabineros (Higuera y Fossa, 2019, 28 de octubre). Algo más que un cambio 
de gabinete es requerido para contener el descontento popular. Por otro lado, las masas avanzan en la conformación de diferentes espacios de deliberación. Amplias Asambleas y Cabildos se celebran en diferentes pueblos y ciudades del país (Akram, 2019; De Mattos y Bravo, 2020, 31 de octubre; Mayol, 2019).

En televisión, los analistas políticos se parapetan en la protección del régimen institucional vigente (24horas.cl, 2019f). Junto con reconocer que ha sido la clave del desarrollo económico chileno, evalúan negativamente las prácticas de democracia directa desplegadas por la población. La Asamblea Constituyente notutelada, o 'libre y soberana' (Grez, 2019), es representada como sinónimo de incertidumbre e inestabilidad. Isabel Aninat intelectual orgánica del régimen - declara en Mesa Central que 'sin partidos no hay democracia' (T13, 2019d). Conforme la situación progresa, el Gobierno agota sus recursos para contener y desviar. La represión ni las promesas de concesiones económicas logran detener el ascenso de masas. Y pese a que el Gobierno ha abandonado su intento de implementar medidas de contrarreforma al bacheletismo, la ciudadanía se encuentra en pie de lucha por cambios sustantivos.

Pero aún así las propuestas legislativas pro-distribución y probienestar del Partido Comunista y Frente Amplio, son representadas por el oficialismo como 'demasiado radicales', 'populistas' e 'inconstitucionales' (Correa, 2019, 8 de noviembre; Rovira, 2020). Sin sospecharlo, quizás, los propios políticos conservadores erigen la Constitución como objeto de la rebelión. En este momento, lo que iniciara como lucha económica deviene en lucha política (Lenin, 2003/1902). La cuestión del poder ya se encuentra en juego. Y en la práctica, la población adhiere ampliamente a la jornada de Huelga General del 12 de octubre. Se trata del episodio más intenso del 'estallido social'. En los medios circulan rumores de una negociación entre Ejército y Ejecutivo para poner fin definitivo a la rebelión (Cooperativa.cl, 2019, 14 de noviembre; Ruíz, 2020). Al anochecer, el Ejecutivo envía un ultimátum a los partidos políticos. Las negociaciones por una salida pactada en el Legislativo deben sellarse lo antes posible (Fossa, Herrero e Higuera, 2019, 13 de noviembre). 
Cuarenta y ocho horas más tarde, en la madrugada del 15 de noviembre - 'entre gallos y medianoche'- se anuncia el 'Acuerdo por la Paz y una Nueva Constitución'. Este fija los mecanismos que derogarán la Constitución actual y que originarán una nueva (CIPER, 2019, 18 de noviembre). Se trata de una salida intermedia entre la Asamblea Constituyente no-tutelada -o 'libre y soberana' (Grez, 2019), promovida por el Partido Comunista y sectores del Frente Amplio- y el Congreso Constituyente promulgado por los sectores conservadores del orden vigente. Con el transcurso de las semanas, esta maniobra evidencia su efectividad en la descompresión de la movilización (CNN Chile, 2019e). Junto con disminuir el volumen de las convocatorias a marchas y concentraciones, también lo hace la participación en Asambleas y Cabildos territoriales. Permanecerá en el entredicho y como objeto de futuras especulaciones si acaso el Gobierno pudo haber caído. Y en tal caso, quién lo hubiera reemplazado.

Con todo, la rebelión sí originó condiciones para la germinación de formas embrionarias de poder dual (Lenin, 1961/1917; Torres, 2020). No obstante, el Acuerdo del 15 de noviembre su objetivo de reconducir un proceso revolucionario en uno de recomposición del régimen vigente. Los defensores del 'Acuerdo' insistirán en que ello se traducirá en una caída definitiva del pinochetismo en Chile (Akram, 2019; Ruíz, 2020). Pero lo más relevante, desde la perspectiva obrera, son los indicadores de avance en la conciencia, combatividad y organización de la clase trabajadora —en su conjunto de capas. Inscritos quedaron en la historia los últimos bastiones de la Fronda chilena (Grez, 2011; Edwards, 1976; (Torres, 2020, pp. 66). Figuras como las de Gabriel Boric y Giorgio Jackson, con la firma del 'Acuerdo', evidenciaron su concertacionismo - expresión contemporánea de la orientación girondina y antisansculotte durante la Revolución francesa. Vale decir, la política pro conciliación con del pueblo con el gran empresariado (Pressaco y Salvat, 2012), además de medidas demagógicas y represión hacia el pueblo movilizado. La lucha de clases en Chile queda, de tal modo, aún por escribirse. 


\subsection{Reestructuración}

Para efectos prácticos, la fase de reestructuración se inaugura con la firma del Acuerdo del 15 de noviembre del 2019. Esta finaliza con breves alusiones al contexto dado entre mayo y agosto del 2020. Entre ellos, las 'revueltas del hambre' de El Bosque, el paro de camioneros en el marco del conflicto del Wallmapu, y los retiros de las AFP. Esto es la apertura del proceso constituyente, el cual marca un punto de inflexión en la rebelión. Es posible intuir que los sectores que logran ser desmovilizados corresponden a aquellos que los estudios de opinión caracterizan como adherentes a las protestas, pero críticos de los métodos de la lucha callejera (Activa, 2019). Se trata de sectores medios, concentrados en rangos de edad de más de 25 años y que se reconocen a sí mismos como 'apolíticos'. El terreno para aprobar medidas 'anti-primera línea' se encuentra preparado en el Legislativo (Vergara, 2019). Con apoyo del Frente Amplio, avanzan medidas que recrudecen las sanciones por desorden público. Entre ellas figuran el saqueo, barricadas, bloqueo del tráfico -y del renombrado 'el que baila pasa'-, el uso de cubre-rostros, entre otras. La fuga de militantes no se deja esperar. Tampoco el quiebre de reconocidos/as cuadros con la coalición (Marín, 2019b, 19 de noviembre).

En el intertanto y hasta fines del año 2019, los medios de prensa atienden de cerca los detalles sobre el proceso constituyente. Es el tema de conversación central en matinales, noticieros, estelares y espacios de análisis político. Tanto los balances de su trasfondo, como las proyecciones de sus resultados, rebasan las pantallas chilenas. El año 2020 inicia con el incendio de la iglesia de Carabineros (T13, 2020a) —en el Barrio San Borja, a pasos de la llamada 'zona cero', correspondiente a la Plaza Italia de Santiago. Se trata de un controvertido episodio, donde encapuchados prendieron fuego a uno de los sitios mejor parapetados por los uniformados. A los pocos días se realiza una misa en el lugar (24horas.cl, 2020). Esta figura como un acto de masas protagonizado por diversas fracciones pinochetistas, las que parecen entrar en un proceso de reagrupamiento. Las organizaciones de ultraderecha asistentes - 
como Voz Nacional y Capitalismo Revolucionario, entre cuyos líderes figuran Johannes Kaiser y Sebastián Izquierdo- anuncian en sus medios de difusión que sus grupos de choque harán pronta aparición en el espacio público.

El 'Acuerdo' fue para las masas apresurado. Su codificación es lenta entre los espacios de deliberación. Muchos de estos caen prontamente en el cosismo. Los sectores adherentes y participantes de la movilización tienden a fraccionarse. Suceden disputas y quiebres en Unidad Social (González, 2020, 21 de enero). La posición de las organizaciones obreras, populares, ambientales, feministas, territoriales, de pueblos originarios, entre otras, no se encuentra definida de cara al proceso constituyente. En general, el 'Acuerdo' es reconocido como un triunfo de la oligarquía, auxiliada por el Frente Amplio y la ex-Concertación. El debate gira en torno a la estrategia que se debe adoptar ante ello. Sectores radicalizados llaman a sabotear el proceso electoral, mientras otros promueven el 'apoyo crítico'. Con todo, la coyuntura durante el período estival evidencia un repliegue de la línea de masas de la movilización. Pero ante los quiebres, se originan nuevas articulaciones a nivel de dirigencias. El debate son ahora las alianzas y perspectivas de lucha - institucional — de cara al conjunto de procesos electorales venideros entre los años 2020 y 2021.

En medios reaccionarios se alerta la necesidad de implementar espionaje y persecución a quienes fueran 'cabecillas' de la rebelión (Garcés, 2020, 22 de enero). Por su parte, en la derecha política comienzan a tomar fuerza figuras que hablan de una 'derecha social' (Del Río, 2020), como Mario Desbordes en Renovación Nacional y Joaquín Lavín en la Unión Demócrata Independiente. El objetivo político de la clase dominante chilena es, por el momento, recomponer sus enlaces rotos con el pueblo tras años de neoliberalismo —o 'capitalismo salvaje' — en Chile. En el plano económico, las controversias distan de aquellas contenidas en los lienzos y pancartas de las calles. Las preocupaciones centrales de Hacienda y del Banco Central son las tareas necesarias para reactivar la economía. Las políticas fiscales y monetarias enfrentan un particular escenario de incertidumbre e inestabilidad. 
Los análisis indican que Chile está tensionado entre lineamientos populistas y autoritarios (Peña, 2020; Rovira, 2020). La orientación girondina insistirá en restablecer y oxigenar los enlaces entre política y sociedad (Fuentes, 2019; Mayol, 2019; Ruíz, 2020). Por el contrario, el autoritarismo — de rasgos bonapartistas - sostendrá la necesidad de vigorizar el liderazgo gubernamental (24horas.cl, 2019g, 19 de diciembre). En tal contexto, el Banco Central decide mantener la tasa de interés (T13, 2019e, 6 de diciembre). La decisión considera la volatilidad de los mercados bursátiles, el alza del dólar y de los indicadores de riesgo país. La política fiscal, por su parte, se presenta en un escenario de déficit presupuestario (Gómez, 2019, 2 de diciembre). Los comunicados oficiales hablan de que los costos del 'estallido' han sido altos. Estos aluden a la atención de demandas sociales, reconstrucción y apoyo a pequeñas y medianas empresas.

Importancia central posee la situación económica mundial, convulsionada por las tensiones comerciales entre China y Estados Unidos. Pero la controversia se instala en torno a las decisiones de Hacienda. La estrategia tomada para mitigar la crisis corresponde a un incremento del endeudamiento público, lo que habla de oportunismo bancario y complicidad gubernamental (Fazio, 2019, 16 de diciembre). A mediados de febrero los indicadores de inflación suscitan revuelo (Diario Financiero, 2019, 11 de febrero). El Banco Central modifica su política marco, atendiendo el ciclo económico y sus crisis periódicas (Marx, 2010/1867). Para ello adopta medidas contracíclicas orientadas a estabilizar las cadenas de pago. Pero en el reverso de la expansión fiscal se ubica el cuestionado endeudamiento.

Los/as economistas encienden las alarmas ante el anuncio de que una nueva enfermedad, etiquetada momentáneamente como Covid-19, amenaza al mundo capitalista (Valdebenito, 2020). Según algunos/as (EmolTV, 2020, 28 de abril; Rojas, 2020, 5 de julio; T13, 2020b, 15 de abril), tal escenario plantea la adopción no-coordinada de políticas de desglobalización. Se trata de un fenómeno que debe ser evaluado empíricamente. Pero en lo práctico, sus consecuencias inmediatas se presentan como la irrupción de un enorme shock de oferta negativo. Esto se relaciona con una ralentización inducida a la 
producción y el comercio, ante la implementación de cuarentenas y distanciamientos en China. Su adopción en Chile se esperará hasta la segunda quincena de marzo. La propagación de la 'triple crisis' -económica, social y sanitaria - en la nación sudamericana será en adelante sólo cuestión de tiempo (BBC News Mundo, 2020). A mediados del mes de mayo estallan las 'huelgas del hambre' (Palma y Pizarro, 2010, 19 de mayo; Vargas y Peña, 2020, 18 de mayo).

Las luchas políticas experimentan tras ellas un punto de inflexión. Quienes durante el estallido actuaran como bastiones del régimen, hoy se presentan a sí mismos como preocupados por el bienestar social. Particularmente controvertido es el giro 'social' que experimentan diversos/as parlamentarios/as del oficialismo (Del Río, 2020). Según algunos/as, esto vaticina un quiebre y reconfiguración en la derecha política chilena. Durante los meses de mayo y junio el Ejecutivo promueve una agenda pro-neoliberal, compuesta por subsidios para sectores populares, líneas de crédito para sectores medios y salvatajes a grandes empresas (Herrero, 2020). Pero esta no logra el apoyo parlamentario necesario para aplicarla íntegramente. En su lugar son erigidas mociones tendientes a intervenir los fondos de ahorro previsional de capitalización individual. Esto se codifica como un misil político al modelo económico chileno (Cataldo y Valdebenito, 2020). Si bien esta no logra resolver problemas como el estancamiento productivo y desigualdad en Chile, pronto el Ejecutivo reconocerá que la medida sí permitió reactivar el consumo (CNN Chile, 2020).

Entre los meses de julio y agosto la coyuntura chilena avanza sobre terreno escarpado. Durante el mes de marzo, hubo signos de radicalización conservadora en sectores de la pequeña burguesía urbana. Estos pese a que intentaron ser contenidos por la derecha política (Meganoticias, 2020), su próxima explosión tuvo lugar en el sur de Chile (El Desconcierto, 2020c). Bajo una articulación de transportistas y latifundistas, estos 'se han levantado contra un gobierno que los ha abandonado ante la violencia narcoterrorista perpetrada por organizaciones de izquierda que instrumentan la causa mapuche en la Araucanía' (El Baquedano, 2020a; 2020b). 
Los medios de masas en Chile no prestaron la atención requerida al resurgimiento del fascismo en Chile. Por el contrario, pareciera ser que en lugar de contribuir a la consolidación del pluralismo informativo, estos se encuentran de lleno en un proceso de marketing y farandulización política de cara al proceso constituyente (Peña y Lillo, et al, 2020).

Allí figuras como la de Joaquín Lavín se han convertido en panelistas permanentes de espacios televisivos como matinales. $\mathrm{Y}$ pese a que hay ciertos/as personeros/as del anti-neoliberalismo que comienzan a adquirir mayor notoriedad en televisión, el trato que reciben de parte de los/as conductores/as es diferenciado. Una vez que explican sus ideas, estos suelen ser interrumpidos. También sus posiciones son públicamente puestas en entredicho por. Por el contrario, a aquellos/as representantes de la ex-Concertación y de la derecha política, se les permite exponer libres de interrupciones o cuestionamientos. Los estudios corroboran que estos últimos gozan de mayor tiempo de exposición en pantalla (Criteria, 2020, pp. 23). Esto permite que sean más reconocidos por la ciudadanía, con la expectativa de promover sus resultados electorales (Mayol, 2019; Ruíz, 2020). Con todo y pese a la abundancia de conjeturas (Chernilo, 2020, 3 de abril; Mascareńo, 2020), los resultados del proceso constituyente permanecen sujetos a la evidencia histórica.

\section{5. - Discusión y CONCLUSiones}

Es importante destacar que las representaciones sobre las fuentes, manifestaciones y propuestas de intervención ante la crisis se diferencian sustancialmente entre sí a partir de sus lineamientos normativos. Estos subyacen a los énfasis y cegueras relativas con que cada agente valora los hitos que articulan su desarrollo empírico. De ahí que el proceso de convulsión general experimentado en Chile desde octubre del año 2019, posea múltiples aproximaciones, como mediáticas, científicas y filosóficas. Aquí se ha concebido que esta corresponde, por sobre un 'imprevisible estallido' (Mayol, 2019), o un desborde de lo social (Tironi, 2020), a una enorme rebelión popular (Grez, 2019). Esto involucra reconocer que a su base se encuentran 
las contradicciones emanadas de la configuración neoliberal de las relaciones de explotación en Chile (Gaudichaud, 2015). Pero en tanto proceso revolucionario, adoleció de una entrada, o dirección coordinada, de los/as trabajadores/as de sectores productivos. Esto permitió facilitar su contención y desvío al interior de los marcos de la institucionalidad vigente, auxiliando de tal modo a la preservación del statu-quo.

Mediática y políticamente, los principales hitos se encuentran en las jornadas del día 18 y 25 de octubre y del 12 y 15 de noviembre del año 2019. Octubre arranca con la violenta irrupción de las masas en el espacio público y finaliza con una enorme y compacta movilización pacifista. Noviembre, por su parte, estuvo marcado por una implacable jornada de insurrección, seguida por la apertura del proceso constituyente. Los antecedentes prácticos son múltiples e imposibles de reducir a eventos particulares. Por ejemplo, la 'huelga del futuro' de julio del 2019, las protestas nacionales de Unidad Social de septiembre, o las evasiones estudiantiles de la primera quincena de octubre. Pero todas estas poseen como antecedente la historia del conjunto de las maniobras populares en la lucha de clases en Chile. A esto se debe el éxito de consignas como 'no son $\$ 30$, son 30 años' - y que algunos corrigieron señalando 'son 500 años', en alusión al conjunto del colonialismo y neoliberalismo en el país.

Tales acontecimientos en los medios de comunicación de masas han tenido una proyección ambivalente. Si bien ha sido extensamente estudiado que en ella prima el discurso de la criminalización (Antezana y Cabalin, 2018; Cárdenas y Pérez, 2017; Gronemeyer y Porath, 2017; Ruíz, 2020), la jornada del 25 octubre constata un giro mediático. Este es precedido por las manifestaciones en las afueras de los canales de televisión del lunes 21 de octubre (Almeida y Riffo, 2019, 22 de octubre). Tras ello, destacarán la legitimidad de las demandas sociales, pero criticando el empleo de métodos violentos. Esto se condice con una mayor presencia de políticos/ as e intelectuales afines al antineoliberalismo desde entonces en espacios de debate televisivo. Pero se debe destacar que su presencia 
no puede ser codificada como de plena inclusión, pues es patente el trato desigual desde conductores, panelistas y periodistas hacia dichos cuadros. Aún así, tal elemento permite oxigenar — desde una perspectiva pluralista - la colisión normativa entre diagnósticos y propuestas de intervención ante los procesos de crisis y lucha de clases en Chile.

De lo anterior se induce que el proceso revolucionario del 2019 impulsó la germinación de una recomposición editorial en los medios de masas en Chile. No obstante, este juicio debiera corroborarse en el futuro, y con mayor evidencia empírica. Por el momento, los primeros análisis indican la prevalencia de la parcialidad periodística al enfrentar personeros/as girondinos/ as y bonapartistas, en desmedro de los/as jacobinos/as, y absoluta marginación de los/as hebertistas — retomando las posiciones de la Revolución francesa. De ahí el reconocimiento de la imposición de la perspectiva de la criminalización a la hora de cubrir episodios de protesta social en la televisión chilena. Vale decir, de aquella superficial y pro-régimen, por sobre una de orientación pluralista y democrática. Esto se expresa en múltiples ejemplos, donde se enfatiza excesivamente en imágenes de 'vandalismo' por sobre la atención a las causas estructurales de tales episodios de lucha social. Se debiera explorar en qué medida tales maniobras mediáticas contribuyen a la propagación de sentimientos como miedo e inseguridad en la población y su impulso al fortalecimiento del fascismo criollo.

Lo anterior puede ser considerado como un antecedente clave a la hora de problematizar la erosión de la confianza ciudadana en la televisión abierta en Chile (Newman, et al, 2020). Especialmente atendiendo a que durante procesos de convulsión, polarización y radicalización política en formaciones democráticas, los medios de masas debieran contribuir al diálogo y encuentro de los sectores (Habermas, 2006; Happer, 2016). Es decir, desde posiciones imparciales y abiertas, por sobre imparciales y cerradas, alineadas con los intereses de los capitales a la base de sus modelos de propiedad. Tal es la relevancia de democratizar los medios de masas, mediante iniciativas como leyes de medios (Becerra, 2019). 
El examen aquí realizado permite constatar que la representación televisiva de las controversias críticas en Chile, es normativamente afín a aquella realizada por periódicos de la derecha política. Futuras aproximaciones que empleen técnicas como análisis de contenidos, semióticos de la imagen y del texto, además de caracterizaciones estadístico descriptivas, podrían profundizar en algunas de las intuiciones aquí esbozadas. Por el momento, queda trazado el camino para la caracterización de los hechos de la rebelión chilena del 2019 y el posicionamiento normativo consecuente del conjunto de aparatos ideológicos del neoliberalismo chileno.

Finalmente, subrayar que uno de los marcos interpretativos de la realidad, que fuera apropiado por las dirigencias e intelectuales del mundo popular, el marxismo, perdura hasta el día de hoy. Y esto pese a la multiplicidad de intentos que han destacado su obsolescencia, anacronismo y/o incompatibilidad con la realidad actual. Por sobre una teoría de la política, del Estado o la ideología, hoy parece reafirmarse como método de estudio para la intervención de la realidad. No obstante, uno de los desafíos pendientes para quienes se posicionan desde allí es el de atender las expresiones ideológicas contemporáneas de las clases dominantes. Entre estas, las miradas de sistemas y de la complejidad social. Pero también aquellas que han logrado penetrar entre los elementos más desorientados de la clase trabajadora - como discursos y perspectivas del reflujo posmoderno. El presente estudio intenta ser un aporte en dicha dirección, pero reconociendo que la tarea va mucho más allá del contraste de análisis. Es necesario avanzar en todo lo que lucha de clases en el terreno de lo político e ideológico exija. Aquí hay sólo una modesta contribución. 
6.- REFERENCIAS

24HORAS.CL. (2019a). Ministro Monckeberg: 'La jornada de trabajo rígida que tenemos no incentiva la productividad' [video]. https://bit.ly/2PnRNpC.

24HORAS.CL. (2019b). Estado Nacional-Domingo 13 de octubre | 24 Horas TVN Chile [video]. https://bit.ly/39SX15X.

24HORAS.CL. (2019c). 24Horas Central-Viernes 18 de Octubre | 24 Horas TVN Chile [video]. https://bit.ly/3fujR58.

24HORAS.CL. (2019d). 24Horas Central - Sábado 19 de Octubre | 24 Horas TVN Chile [video]. https://bit.ly/3ftMOhw.

24HORAS.CL. (2019e, 12 de noviembre). CUT realiza balance por paro general de este martes: 'Este es un ultimátum al Gobierno'. 24horas.cl. https://bit.ly/2EWDp5y.

24HORAS.CL. (2019f). Estado Nacional-Domingo 3 de noviembre | 24 Horas TVN Chile [video]. https://bit.ly/2XFa4Da.

24HORAS.CL. (2019g, 19 de diciembre). Evelyn Matthei tras crisis social: 'Chile cambió para mal y cambió para siempre yo creo que esto es irrecuperable'. 24 Horas. https://bit.ly/3grzjjU. 24HORAS.CL. (2020, 5 de enero). Misa de Carabineros en iglesia quemada termina con funa de manifestantes. 24 horas. https:// bit.ly/3kIXo8h.

ACEVEDO, E. (2012, 12 de julio). Informe Especial: Súper ricos en un país desigual. 24 Horas. https://bit.ly/3fsxDVX.

ACTIVA. (2019). Pulso Ciudadano: Crisis en Chile. https://bit. ly/2XFvmAT.

AKRAM, H. (2020). El Estallido. ¿Por qué? ¿Hacia dónde? Santiago de Chile: Ediciones y Publicaciones El Buen Aire.

ALMEIDA, A. y Riffo, J. (2019, 22 de octubre). Furia contra canales de TV por cobertura sesgada los obliga a mostrar la represión. Interferencia. https://bit.ly/2ZHrb7A.

ANTEZANA Barrios, L. y Cabalin, C. (2018). Memorias en conflicto en la esfera pública chilena: ficción televisiva $\mathrm{y}$ dictadura. Anàlisi. Quaderns de Comunicació i Cultura, (58), pp. 105-119. https://doi.org/10.5565/rev/analisi.3128.

ARBOLEDA, M. (2020). Planetary Mine. Territories of Extraction under Late Capitalism. Londres y Nueva York: Verso. 
AURORA SOBERANA [Aurora Soberana]. (2019, 6 de diciembre). Evento de Voz Nacional - Exposición de Johannes Kaiser [Archivo de video]. Recuperado de https://bit.ly/3fSKdxW. AVENDAÑO, E. (2019, 22 de octubre). Los «chalecos amarillos» chilenos que protegen sus barrios versus los franceses que se toman las calles. El Libero. https://bit.ly/31avqJE.

BBC News Mundo. (2020). Claves para entender la triple crisis que atraviesa Chile |BBC Mundo [video]. https://bit.ly/3grsPkT.

BECERRA, M. (2019). Public Broadcasting: The Latin American Exception. The Political Economy of Communication, 7(1), pp. 105-109.

BOULIANNE, S., Koc-Michalska, K. y Bimber, B. (2020). Rightwing populism, social media and echo chambers in Western democracies. New media or society, 22(4), pp. 683-699. https:// doi.org/10.1177/1461444819893983.

CALLINICOS A. (2015). Neoliberalism, Austerity, and Crisis. En: Pereira A.W., Mattei L. (Eds.), The Brazilian Economy Today. Londres: Palgrave Macmillan. https://doi. org/10.1057/9781137549815 2.

CANAL 13. (2019). Los usuarios opinan sobre las evasiones en el Metro de Santiago | Bienvenidos [video]. https://bit.ly/2PByJEu.

Cárdenas, C. y Pérez, C. (2017). Representación mediática de la acción de protesta juvenil: la capucha como metáfora. Revista Latinoamericana de Ciencias Sociales, Niñez y Juventud, 15(2), pp. 1067-1084. https://bit.ly/2Pyq8T3.

CASTELLS, M. (2017). Ruptura. La crisis de la democracia liberal. Madrid: Alianza Editorial.

CATALDO, C., \& Valdebenito, J. (2020, 13 de julio). ¿El fin de las AFP? Reflexiones ante la histórica sesión parlamentaria del 8 de julio, 2020. Revista Rosa. https://bit.ly/30WYdT5.

CEP. (2017). ¿Malestar en Chile? Santiago de Chile: Centro de Estudios Públicos. https://bit.ly/33yDYgi.

CHERNILO, D. (2020, 3 de abril). 5 escenarios para un mundo post-pandemia. CIPER. https://bit.ly/3fkUd2I. 
CHILEVISIÓN. (2019). DESDE EL AIRE: La marcha más grande de CHILE desde el cielo - Contigo en La Mañana [video]. https:// bit.ly/2DzKEzW.

CHV Noticias. (2019, 17 de octubre). Protestas por el alza de tarifa: Caos en el Metro por evasión masiva. CHV Noticias. https:// bit.ly/30EE6cd.

CIPER (262 profesores y profesoras de derecho y ciencia política). (2019, 18 de noviembre). 'El Acuerdo por la Paz Social y la Nueva Constitución' no es una trampa. CIPER. https://bit. ly/2XGpV14.

CNN Chile. (2020, 12 de agosto). Ministro Palacios reconoce que el retiro del $10 \%$ está reactivando la economía. CNN Chile. https://bit.ly/3kOwA6v.

CNN Chile. (2019a, 10 de julio). Walmart: La huelga del futuro. CNN Chile. https://bit.ly/2XmAJV6.

CNN Chile. (2019b, 19 de octubre). ¿Qué implica que el gobierno de Chile declare estado de emergencia? CNN Chile. https://bit. ly/3gCpqQc.

CNN Chile. (2019c). General Iturriaga: 'Soy un hombre feliz, no estoy en guerra con nadie' [video]. https://bit.ly/31zFBri.

CNN Chile. (2019d, 5 de noviembre). 'Chalecos amarillos' se enfrentan con manifestantes en Reñaca: Hubo una agresión con un bate. CNN Chile. https://bit.ly/2PnMc2k.

CNN Chile. (2019e, 20 de diciembre). Carabineros estima que en diciembre han habido $142 \mathrm{mil}$ asistentes a manifestaciones. CNN Chile. https://bit.ly/3ko44IG.

COLLADOS, A. (2020, 17 de febrero). ¿Por qué la derecha dura se siente traicionada por el Gobierno? La Segunda, pág. 6.

COOPERATIVA.CL. (2019, 14 de noviembre). Alcalde UDI sostiene que Fuerzas Armadas exigieron 'garantías' a Piñera. Cooperativa. https://bit.ly/3a859zN.

CORREA, R. (2019, 8 de noviembre). Para superar el problema constitucional: una propuesta alternativa. CIPER. https://bit. ly/2C8RTyl.

CRITERIA. (2020). Agenda Criteria: Junio 2020. Santiago: Criteria. 
DE CASTRO, S. (1992). El Ladrillo: bases de la politica económica del gobierno militar chileno. Santiago de Chile: Estudios Públicos.

DE MATTOS, N. y Bravo, D. (2019, 31 de octubre). Colo-Colo, Feminismo separatista y Unidad Social en Providencia: Así se vivieron algunos de los cabildos autoconvocados por la ciudadanía. El Desconcierto. https://bit.ly/2DsmtmO.

DEL RÍO, S. (2020, 15 de junio). Los polémicos proyectos de ley de la izquierda que "sedujeron" a parlamentarios de derecha. $E l$ Libero. https://bit.ly/341wSkw.

DIARIO FINANCIERO. (2019, 11 de febrero). Banco Central actualiza marco de la política monetaria. Diario Financiero. https://bit.ly/30pmQYp.

DÍAZ, W. (2019, 26 de octubre). José Miguel Insulza, senador PS: 'Mientras más ninguneamos la política, más nos alejamos de la solución'. El Mercurio. https://bit.ly/3grJqVV.

DONIEZ, V. y Gálvez, R. (2020). Reformas en tiempos de crisis: Análisis critico de la agenda laboral del gobierno. Santiago de Chile: Fundación SOL. https://bit.ly/3i3CWN9.

EDWARDS, A. (1976). La fronda aristocrática, historia politica de Chile. Santiago de Chile: Del Pacífico.

EIROA, M. y Barranquero, A. (2017). Métodos de investigación en la comunicación y sus medios. Madrid: Síntesis.

EL BAQUEDANO [El Baquedano]. (2020a, 11 de agosto). Camioneros y Agricultores al borde del paro nacional. Entrevista a Gloria Naveillán [Archivo de video]. Recuperado de https://bit.ly/2PShVt1.

EL BAQUEDANO [El Baquedano]. (2020b, 12 de agosto). ¿Camioneros a La Moneda? Entrevista al Presidente de la FEDESUR, José Villagrán [Archivo de video]. Recuperado de https://bit.ly/347xapY.

EL DESCONCIERTO. (2020, 2 de agosto). Civiles atacan a comuneros mapuche en toma durante violenta noche de incendios y enfrentamientos. El Desconcierto. https://bit. ly/2DJTFa3. 
EL DESCONCIERTO. (2019a, 10 de noviembre). Colegio de Periodistas rechaza extorsión económica de empresario Juan Sutil a CNN y Chilevisión. El Desconcierto. https://bit. ly/2Dm9uUb.

EL DESCONCIERTO. (2019b, 8 de noviembre). El mensaje de David Veloso tras ser puesto en libertad: 'Quiero darle un saludo enorme a todo el pueblo de Chile que está peleando'. El Desconcierto. https://bit.ly/2D8zaDH.

EL DÍNAMO. (2019, 23 de octubre). VIDEO | Militares juegan voleibol con manifestantes en Vińa del Mar. El Dínamo. https://bit.ly/3aaCc6b.

EL MOSTRADOR. (2019, 24 de octubre). Militar alza bandera Mapuche en plena manifestación ciudadana. El Mostrador. https://bit.ly/33FjdQa.

EMOLTV. (2020, 28 de abril). Daño institucional, impacto social y 'desglobalización': Expertos abordan crisis en la economía post-covid-19. Emol. https://bit.ly/3gDxdO1.

EVANS, B. M. y McBride, S. (2017). The austerity state: an introduction. En: McBride, S. M. y Evans, B. (Eds), The Austerity State. Toronto: University of Toronto Press, pp. 3-24. FAZIO, H. (2019, 16 de diciembre). Hugo Fazio: La desigualdad y el estallido social. El Siglo. https://bit.ly/3k8NLzC.

FOLKE, C., Biggs, R., Norström, A. V., Reyers, B. \& Rockström, J. (2016). Social-ecological resilience and biosphere-based sustainability science. Ecology and Society, 21(3), p. 41. http:// dx.doi.org/10.5751/ES-08748-210341.

FOSSA, L., Herrero, V. e Higuera, C. (2019, 13 de noviembre). FF.AA. se niegan a nuevo Estado de Emergencia, obligando a Pińera a recurrir a policías retirados para agenda de seguridad. Interferencia. https://bit.ly/33p5xJ0.

FOSTER, J. B. (2016). Marxism in the Anthropocene: Dialectical Rifts on the Left. International Critical Thought, 6(3), pp. 393421. https://doi.org/10.1080/21598282.2016.1197787.

FUENTES, C. (2019). La erosión de la democracia. Santiago de Chile: Catalonia. 
GÁRATE, M. (2012). La revolución capitalista de Chile: 1973-2003. Santiago de Chile: Universidad Alberto Hurtado.

GARCÉS, B. (2020, 22 de enero). El movimiento de ultraizquierda que domina Plaza Italia y que organiza nuevo estallido para marzo. El Libero. https://bit.ly/3fVHpjt.

GAUDICHAUD, F. (2015). Las fisuras del neoliberalismo chileno. Santiago de Chile: Quimantú.

GÓMEZ, M. (2019, 2 de diciembre). Chile tendrá en 2020 el mayor déficit fiscal de los últimos 30 ańos. Pauta. https://bit. ly/2BVXvvN.

GONZÁLEZ, T. (2020, 21 de enero). Marginaciones y disputas por el protagonismo amenazan la "Unidad Social". Diario UChile. https://bit.ly/3kKC5Dl.

GREZ, S. (2011). La ausencia de un poder constituyente democrático en la historia de Chile. Tareas, (139), pp. 67-94. https://bit.ly/3hXMgSK.

GREZ, S. (2019). Rebelión popular y proceso constituyente en Chile. En Artaza, P., Candina, A., Esteve, J., Folchi, M., Grez, S., Guerrero, C., Martínez, J., Matus, M., Peñaloza, C., Sanhueza, C. y Závala, J. (2019). Chile despertó: lecturas desde la Historia del estallido social de octubre. Santiago de Chile: Universidad de Chile.

GRONEMEYER, M. E. y Porath, W. (2017). Tendencias de la posición editorial en diarios de referencia en Chile: $\mathrm{El}$ arte de dosificar la crítica frente a la actuación de los actores políticos. Revista de ciencia politica, 37(1), pp. 177-202. https://dx.doi. org/10.4067/S0718-090X2017000100008.

HABERMAS, J. (2006). Political Communication in Media Society: Does Democracy Still Enjoy an Epistemic Dimension? The Impact of Normative Theory on Empirical Research. Communication Theory, 16, (4), pp. 411-426.

HAPPER, C. (2016). Financialisation, media and social change. New Political Economy, 22(4), pp. 437-449. https://doi.org/10 $.1080 / 13563467.2017 .1259301$. 
HERRERA, H. (2019). Octubre en Chile. Acontecimiento y comprensión politica: hacia un republicanismo popular. Santiago de Chile: Kankatura.

HERRERO, V. (2020). Briones presenta plan de rescate de 'grandes empresas estratégicas', pero sólo habla de Latam. Interferencia. https://bit.ly/2Dzf3hT.

HIGUERA, C. y Fossa, L. (2019, 28 de octubre). ¿Normalidad? Aumentan casos de violaciones a DD.HH. este fin de semana. Interferencia. https://bit.ly/2XE73Df.

IMF. (2019, 19 de junio). El personal del FMI concluye su visita a Chile. IMF. https://bit.ly/3frIj76.

INTERFERENCIA. (2019, 20 de octubre). 'No es por 30 pesos, es por 30 ańos'. Interferencia. https://bit.ly/2XDoaoP.

IPSOS. (2020). Coronavirus en Chile, Medición 4. IPSOS. https:// bit.ly/2ZErpfM.

KOSELLECK, R. (1998). Critique and Crisis. Enlightenment and the Pathogenesis of Modern Society. Cambridge/Massachusetts: The MIT Press.

LENIN, V. I. (1902/2010). ¿Qué hacer? Caracas: Ministerio del Poder Popular para la Comunicación y la Información.

LENIN, V. I. (1905/2003). Dos tácticas de la socialdemocracia en la revolución democrática. Marxists Internet Archive. https://bit. ly/3ih7cEH.

LENIN, V. I. (1915/2014). La bancarrota de la Segunda Internacional. Madrid: Fundación Federico Engels.

LENIN, V. I. (1917/1961). Obras escogidas. Tomo II. Moscú: Progreso. https://bit.ly/2XulF83.

LUHMANN, N. (1984) The self-Description of society: Crisis fashion and sociological theory. Journal of Comparative Sociology, 25(1-2), pp. 59-72.

MARCHETTI, P. (2019, 21 de octubre). Bolsa de Santiago se desploma casi $5 \%$ este lunes y vive su peor jornada en dos ańos. Emol. https://bit.ly/31dGNAB.

MARÍN, V. (2019a, 14 de noviembre). Grupo de diputados de oposición se descuelga de negociación: exigen consulta por asamblea constituyente. Emol. https://bit.ly/3ijhd3Z. 
MARÍN, V. (2019b, 19 de noviembre). ¿Quiebre definitivo en el Frente Amplio? Acuerdo constitucional desata la crisis más compleja del bloque desde su formación. Emol. https://bit. ly/3fYQ6JO.

MARTÍNEZ-SALGADO, C. (2012). El muestreo en investigación cualitativa. Principios básicos y algunas controversias. Ciencias y Salud Colectiva, 3(17), pp. 613-619.

MARX, K. (2003/1871). La guerra civil en Francia. Madrid: Fundación Federico Engels.

MARX, K. (2010/1867). El Capital. Tomo I/Vol. 1. Ciudad de México: Ed. Siglo XXI.

MASCAREÑO, A. (2018). De la crisis a las transiciones críticas en sistemas complejos: Hacia una actualización de la teoría de sistemas sociales. Theorein. Revista de Ciencias Sociales, 3(3), pp. 109-143. https://doi.org/10.26807/theorein.v3i1.19.

MASCAREÑO, A. (2020). La mejor futurología depende del futuro. Consideraciones sociológicas sobre la pandemia. Puntos de Referencia, (535). https://bit.ly/2BTT9Fi.

MASCAREÑO, A., Goles, E. y Ruz, G. (2016). Crisis in complex social systems: A social theory view illustrated with the chilean case. Complexity, 21(S2), pp. 13-23.

MAYOL, A. (2019). Big Bang. Estallido Social 2019. Modelo derrumbado, sociedad rota, politica inútil. Santiago de Chile: Catalonia.

MEGANOTICIAS. (2019a, 8 de octubre). Piñera y Chile en Latinoamérica: 'Es un verdadero oasis, con una democracia estable'. Meganoticias. https://bit.ly/319V3u8.

MEGANOTICIAS. (2019b). Manifestantes se enfrentan a militares en Plaza Italia [video]. https://bit.ly/30pIWtV.

MEGANOTICIAS. (2019c). Meganoticias Prime - Martes 12 de noviembre 2019 [video]. https://bit.ly/2F3LlCc.

MEGANOTICIAS.CL. (2020, 12 de marzo). UDI presenta denuncia en contra de Sebastián Izquierdo por presunto delito de amenazas. Meganoticias. https://bit.ly/341ADGA. 
MORALES, J. (2018). Dominación filantrópica y gobernabilidad democrática: el caso de la Fundación Ford y CIEPLAN en Chile (1976-1990). Revista Historia, Universidad Católica de Chile, 1(51), pp. 141-163. http://dx.doi.org/10.4067/s071771942018000100141.

MOUFFE, C. (2007). En torno a lo politico. Buenos Aires: Fondo de Cultura Económica.

NAVARRO, F. y Tromben, C. (2019). 'Estamos en guerra contra un enemigo poderoso, implacable': los discursos de Sebastián Piñera y la revuelta popular en Chile. Literatura y lingüistica, (40), pp. 295-324. https://dx.doi.org/10.29344/0717621x.40.2083.

NEWMAN, N., Fletcher, R., Schulz, A., And1, S. y Nielsen, R. K. (2020). Reuters Institute Digital News Report 2020. Oxford: Reuters Institute for the Study of Journalism, University of Oxford. https://bit.ly/3gq2Z0m.

PALMA, S. y Pizarro, C. (2020, 19 de mayo). 'El estallido del hambre': Dirigentes y vecinos de El Bosque explican las razones de la nueva crisis social. El Desconcierto. https://bit. ly/3fEFHmC.

PEŃA Y LILLO, M., Rocamora, V., Palma, K., Cabalin, C., \& Rodríguez, C. (2020, 17 de julio). Una vuelta radical hacia una comunicación pública e inclusiva. CIPER. https://bit. ly/2Y1umXA.

PEÑA, C. (2019). Pensar El Malestar. La Crisis De Octubre Y La Cuestión Constitucional. Santiago de Chile: Taurus.

PEÑA, C. (2020). La revolución inhallable. Estudios Públicos, (158), pp. 7-29. https://doi.org/10.38178/07161115/2020.001.

PINTO, I. (2019). Imágenes que importan: movimientos sociales, malestar y neoliberalismo en documentales chilenos post2011. Revista de Humanidades, (39), pp. 355-384. https://bit. ly/2DxUn9C.

PINTO, J. (2011). ¿La tendencia de la masa al reposo? El régimen portaliano enfrenta al mundo plebeyo, 1830-1851. Historia, 2(44), pp. 401-442. 
PNUD. (2017). DESIGUALES. Orígenes, cambios y desafíos de la brecha social en Chile. Santiago de Chile: Programa de las Naciones Unidas para el Desarrollo. https://bit.ly/2F3CQag.

PRESSACCO, C. F. y Salvat, P. (2012). Consideraciones críticas sobre política pública y social de los gobiernos Concertación: Chile, 1990-2010. ¿Del crecimiento con equidad al crecimiento basado en la competencia y el subsidiarismo generalizado? Papel Politico, 17(1), pp. 85-118. https://bit.ly/3i83yNh.

RAMÍREZ, N. (2019, 9 de diciembre). Chile se ubica en el lugar 42 en Índice de Desarrollo Humano, pero es el país más desigual dentro de los 50 primeros. Emol. https://bit.ly/31ywvej.

RIGAUD, K.K., de Sherbinin, A., Jones, B., Bergmann, J., Clement, V., Ober, K., Schewe, J., Adamo, S., McCusker, B., Heuser, S., and Midgley, A. (2018). Groundswell: Preparing for internal climate migration. Washington, D.C.: World Bank. https://doi.org/10.1596/29461.

ROBERTS, M. (2018). World in Crisis. Chicago: Haymarket Books. ROJAS, M. (2020, 5 de julio). Mauricio Rojas: El debate sobre el futuro del capitalismo en tiempos de pandemia. El Líbero. https://bit.ly/3krJ0kz.

ROMERO, M. (2019, 23 de noviembre). La reinvención del rol de la Primera Dama en medio de la crisis social que sacude Chile. Emol. https://bit.ly/33Q1CYr.

ROMERO, N. (2019, 26 de octubre). Carabineros reciben 'gratificación especial' para resguardar el orden y la seguridad. El Desconcierto. https://bit.ly/2DvkiiI.

ROVIRA, C. (2020). El error de diagnóstico de la derecha chilena y su encrucijada actual. Estudios Públicos, (158), pp. 31-59. https://doi.org/10.38178/07161115/2020.002.

RUIZ, C. (2020). Octubre Chileno. España: Taurus.

SALAZAR, G. (2019). El Ejército de Chile y la soberania popular. Santiago de Chile: Debate.

SAPIEZYNSKA, E. (2014). Los No Aparecidos: la Protesta Social Invisible en los Grandes Medios en Chile y las Políticas Mediáticas del Disenso. Comunicación y Medios, (29). pp. 156170. 
SOLIMANO, A. (2014). Economic Elites, Crises, and Democracy. Alternatives beyond Neoliberal Capitalism. New York: Oxford University Press.

STAHL, R. M. (2019). Ruling the Interregnum: Politics and Ideology in Nonhegemonic Times. Politics \& Society, 47(3), pp. 333-360. https://doi.org/10.1177/0032329219851896.

STANDRING, A. y Davies, J. (2020). From crisis to catastrophe: The death and viral legacies of austere neoliberalism in Europe? Dialogues in Human Geography, 10(2), pp. 146-149. https:// doi.org/10.1177/2043820620934270.

STRAUSS, A. \& Corbin, J. (2002). Bases de la investigación cualitativa. Técnicas y procedimientos para desarrollar la teoría fundamentada. Medellín: Editorial Universidad de Antioquía.

T13. (2019a, 13 de octubre). [VIDEO] MESA CENTRAL: CAPÍTULO 28 - DOMINGO 13 DE OCTUBRE DE 2019. T13. https://bit.ly/3grMtgy.

T13. (2019b). Violenta jornada de protestas genera caos en Santiago por alza del Metro [video]. https://bit.ly/33mPzy].

T13. (2019c, 25 de octubre). Piñera tras histórica marcha: 'Todos hemos escuchado el mensaje, todos hemos cambiado'. T13. https://bit.ly/3gvtt0Q.

T13. (2019d). Ministro Blumel y senadores Lagos Weber y Allamand en Mesa Central - 10 de noviembre [video]. https://bit.ly/3fl5ccs.

T13. (2019e, 6 de diciembre). Banco Central completa venta de los primeros US $\$ 2000$ millones y tipo de cambio cae $\$ 50$ desde anuncio. T13. https://bit.ly/3gsQLEx.

T13. (2020a, 3 de enero). Se registra incendio en Iglesia Institucional de Carabineros San Francisco de Borja. T13. https://bit. ly/3ar9NJt.

T13. (2020b, 15 de abril). Coronavirus: por qué la pandemia puede acelerar la desglobalización de la economía mundial. T13. https://bit.ly/3adpyDx.

TEUBNER, G. (2012). Constitutional Fragments: Societal Constitutionalism and Globalization. Oxford: Oxford University Press. 
TIRONI, E. (2020). El desborde. Vislumbres y aprendizajes del 18-O. Santiago de Chile: Planeta.

TORRES, F. (2020). Chile convulso. Diario de una rebelión. Santiago de Chile: Entelequia.

TVN. (2017). Una vida rodeada de lujos | 21 días [video]. https:// bit.ly/3i75Xrc.

TVN. (2019). Ministro Monckeberg explica propuesta para flexibilizar la jornada laboral $\mid M B D$ [video]. https://bit.ly/2XorweW.

TVN. (2020). Misión, visión y valores. TVN Corporativo. https:// bit.ly/39WOwH5.

VALDEBENITO, J. (2020). Crisis, televisión, y Covid-19 en Chile (primer semestre 2020). Amoxtli (5), pp. 1-38. http://doi. org/10.5281/zenodo.4377325.

VARGAS, F. y Peńa, J. (2020, 18 de mayo). Protestas en la comuna de El Bosque: Vecinos denuncian falta de alimentos en medio de cuarentena. Emol. https://bit.ly/3fzDF77.

VELASCO, A. (2019, 18 de octubre). Ahora en DF: Reunión de emergencia en la Moneda por disturbios en Metro. Diario Financiero. https://bit.ly/3gq91ON.

VERGARA, C. (26 de diciembre de 2019). Sobre la ley antiencapuchados y otras adaptaciones legales fascistas. CIPER. https://bit.ly/3anNjZM.

\section{Notas}

${ }^{1}$ Investigación realizada gracias a Beca ANID de Doctorado Nacional y al Doctorado en Estudios Interdisciplinarios de la Universidad de Valparaíso. El trabajo forma parte de la tesis doctoral del autor, quien declara no tener ningún tipo de conflicto de interés vinculado a su elaboración. La redacción del artículo finaliza en el mes de agosto del ańo 2020, por lo que eventuales omisiones o exclusiones hacia procesos ocurridos, y literatura publicada, posteriores a tal fecha se deben a dicha situación. Se suman reconocimientos especiales a Cristián Cataldo, Rocío Knipp, Esteban Hoogma, Elisabeth Simbürger, Andrés Barriga, Alejandra Guerra e Ignacio Cáceres. 
Fecha recepción: 11 diciembre de 2020 Fecha aceptación: 11 de enero de 2021 Fecha versión final: 29 de enero de 2021 